\title{
Hepatocellular Carcinoma in Hepatitis C Virus Cirrhosis After Treatment with Direct Acting Antiviral Therapy
}

\author{
M.S.El-Kady, N.E.El-Toukhy and M.S.Abd El-Wahhab
}

Hepatology, Gastroenterology and Infectious Diseases, , Dept., Faculty of Medicine, Benha Univ., Benha, Egypt E-mail: M.S.Abd El-Wahhab@gmail.com

\begin{abstract}
Aim: this study aimed to clarify the possible effect of direct acting antivirals (DAAs) treatment on development of hepatocellular carcinoma (HCC) in hepatitis C virus (HCV) cirrhotic patients. , Methods: this study was conducted on 400 chronic hepatitis $\mathrm{C}$ cirrhotic patients, divided into two groups according to treatment with DAAs, group I including (200 Patients with chronic HCV cirrhosis treated with DAAs), and group II including (200 patients with chronic HCV cirrhosis without DAAs treatment), all patients were recruited from the Gastroenterology and Hepatology department Kobry Elkobba Military Hospital, all patients were males with no previous history of HCC, human immunodeficiency virus (HIV) or hepatitis B virus (HBV) infection or history of liver transplantation. After one year of follow up all patients were divided into further two subgroups according HCC development, group III ( $11 \mathrm{HCV}$ cirrhotic patients treated with DAAs (sofosbuvir and daclatasvir) and developed HCC) and group IV (22 HCV cirrhotic patients not treated and developed HCC). Results: HCC developed more in not treated group with a significant difference as $11 \%$ of not treated group developed HCC compared to $5.5 \%$ only of treated group $(\mathrm{P}=0.046)$. using univariate cox regression, it was shown that no treatment was an independent risk factor of getting hepatocellular carcinoma (HCC), as cases not receiving the study treatment are at higher risk for developing $\mathrm{HCC}(\mathrm{HR}=3.4, \mathrm{P}=0.002)$. conclusion: DAA treatment is not associated with a higher risk of HCC in cirrhotic patients with chronic HCV infection in the short-term. The occurrence of HCC is significantly decreased in patients treated with DAAs.
\end{abstract}

Keywords: Hepatocellular Carcinoma, Hepatitis C, Direct Acting Antiviral, DAAs, HCC.

\section{Introduction}

Hepatocellular carcinoma (HCC) is the most common primary hepatic malignancy of adults. It is the sixth most common cancer worldwide and the third most common cause of cancer death [1].

In Egypt, liver cancer forms $11.75 \%$ of the malignancies of all digestive organs and $1.68 \%$ of the total malignancies. HCC constitutes $70.48 \%$ of all liver tumors among Egyptians [2].

Hepatitis $\mathrm{C}$ virus (HCV), and its long-term resultant consequences, is a major endemic medical health problem in Egypt having taken a representative sample of the country, from both urban and rural areas, an Egyptian demographic health survey conducted in 2008 concluded that $14.7 \%$ of the population have been infected, making this the highest prevalence in any population in the world [3].

The HCV infection is, however, still a current risk factor for HCC. The HCV virus, unlike the HBV virus, does not integrate into the genome and its oncogenic power seems to be related primarily to the effect of chronic inflammation with the progressive development of fibrosis and cirrhosis [4].

Recently, new antiviral therapies with interferon-free medications have been introduced, such as the direct-acting antivirals (DAA) treatments, which have shown a high effectiveness with Sustained virological response (SVR) rates above $90 \%$ [5].
Such therapies stop the necro-inflammatory activity, preventing the progression of fibrosis to cirrhosis and possibly reducing the risk of HCC [6].

Currently, in Italy, the prescription status of DAA is reserved for advanced forms of liver disease such as severe fibrosis (F3 Metavir) and cirrhosis (F4 Metavir). The high rate of viral clearance achieved with DAA turns off the necroinflammatory activity and through the stimulus chronic irritation; however, the inveterate cirrhotic architecture is a condition difficult to reverse and is potentially oncogenic. These components comprise a possible residual risk of $\mathrm{HCC}$, and therefore cannot be established, at present, which is the real influence of the DAA [7].

The purpose of this study was to clarify the possible effect of DAAs treatment on development of $\mathrm{HCC}$ in $\mathrm{HCV}$ cirrhotic patients.

\section{Patients and methods}

This prospective study was carried out on patients attending gastroenterology and hepatology department Kobry El Kobba military hospital. The study included $400 \mathrm{HCV}$ cirrhotic patients selected from 8300 patients according to inclusion and exclusion criteria.

Patients divided in the study according to treatment into 2 groups:

- Group I: $200 \mathrm{HCV}$ cirrhotic patients treated with DAAs (sofosbuvir and daclatasvir).

- Group II: 200 HCV cirrhotic patients not treated. 
The SVR is defined as the absence of HCV RNA at 12 weeks after the end of therapy.

After one year of follow up. All patients were devided into further two subgroups according HCC development:

- Group III: $11 \mathrm{HCV}$ cirrhotic patients treated with DAAs (sofosbuvir and daclatasvir) and developed HCC.

- Group IV: $22 \mathrm{HCV}$ cirrhotic patients not treated and developed HCC.

\subsection{Inclusion criteria}

- Patients chronically infected with HCV confirmed by HCV RNA positive PCR.

- Patients $>18$ years old and $<70$ years old.

- Patients with platelet count $>50,000 / \mathrm{mm} 3$.

- Patients with hemoglobin level $>10 \mathrm{~g} / \mathrm{dl}$.

- Patients with Child Turcotte-Pugh (CTP) class A or B liver cirrhosis.

- Patients without history of previous HCC.

\subsection{Exclusion criteria}

- Patients with HBV co-infection.

- Patients with HIV co-infection.

- Patients $>70$ years.

- Patients with bleeding tendency.

- Patients with history of Hepaocellular Carcinoma.

- Patients with platelats count $<50,000 / \mathrm{mm} 3$.

- Patients with a dubious focal lesion, which were detected prior to starting the therapy.

- HCV positive patients after liver transplantation.

- Patients with hemoglobin level $<10 \mathrm{~g} / \mathrm{dl}$.

- Patients with Child Turcotte-Pugh (CTP) class C.

All patients were subjected to full history taking, clinical examination, laboratory investigation amd abdominal US. HCC was diagnosed by ultrasound and confirmed by triphasic CT

Written consent was taken from all patients.

\subsection{Statistical analysis}

Data were collected, revised, coded and entered to the Statistical Package for Social Science (IBM SPSS) version 20. Qualitative data were presented as number and percentages while quantitative data were presented as mean, standard deviations and ranges when parametric. The comparison between groups regarding qualitative data was done by using Chi-square test. The comparison between two groups regarding quantitative data with parametric distribution was done by using Independent t-test. The comparison between more than two paired groups regarding quantitative data with parametric distribution was done by using Repeated Measures ANOVA. Univariate cox regression analysis was used to assess the hazardous risk ratio of $\mathrm{HCC}$ development. The confidence interval was set to $95 \%$ and the margin of error accepted was set to $5 \%$. So, the p-value was considered significant as the following:

\section{Results}

All cases included in the study were adult males as hospital protocol. There is no statistical significant difference between treated and non treated groups as regards age. also non treated group is from rural residence slightly more than treated group with no statistical significant difference, table (1).

No statistical significant difference between studied patients as regards Ultrasonograhic findings. table (2).

Also no statistical significant difference between studied patients as regards Child classification. table (3).

The non treated group AFP is statistically higher than treated group. table (4).

There is significant difference between treatment and non treated groups as regards development of HCC, as $11 \%$ of non treated group developed HCC compared to $5.5 \%$ only of treated group. table 5 and figure (1).

There was a significant difference between treatment and non treated groups as regards HCC criteria as in non treated group the focal lesion is mostly: multiple lesions, large sized lesions, bilobar lesions, association with $\mathrm{LN}$ and association with portal vein thrombosis. table (6).

The non treated group with HCC (group IV) hemoglobin is slightly lower than treated group with HCC (group III) with statistical significant difference. Also showed no statistical significant difference between treated group with HCC (group III) and non treated group with HCC (group IV) as regards white blood cells count and Platelets . table (7).

The non treated group with HCC (group IV) total bilirubin is higher than treated group with HCC (group III) with statistical significant difference. Also, non treated group with HCC (group IV) creatinine is higher than treated group with HCC (group III) with statistical significant difference. there is no statistical significant difference between treated group with HCC (group III) and non treated group with HCC (group IV) as regards ALT, AST, direct bilirubin, albumin and INR. table 8 .

Using univariate cox regression, it was shown that no treatment with DAAs was an independent factor affecting the risk of getting hepatocellular carcinoma (HCC), as cases not receiving the study treatment are at higher risk for developing HCC $(\mathrm{HR}=3.4, \mathrm{P}=0.002)$. table 9 and Figure (2). 
Table (1) Demographic characteristics of studied patients.

\begin{tabular}{|c|c|c|c|c|c|c|}
\hline & & \multicolumn{2}{|c|}{$\begin{array}{l}\text { Group I (Treated) } \\
\qquad \mathbf{N}=\mathbf{2 0 0}\end{array}$} & \multicolumn{2}{|c|}{ Group II (non treated) } & \multirow{2}{*}{ P-value } \\
\hline & & Mean & $\pm \mathrm{SD}$ & Mean & \pm SD & \\
\hline \multirow[t]{2}{*}{ Age } & & 63.02 & 6.86 & 64.24 & 6.49 & 0.06 \\
\hline & & $\mathbf{n}$ & $\%$ & $\mathbf{n}$ & $\%$ & \\
\hline \multirow{2}{*}{ residence } & rural & 103 & $51.5 \%$ & 106 & $53.0 \%$ & 0.7639 \\
\hline & urban & 97 & $48.5 \%$ & 94 & $47.0 \%$ & 0.8413 \\
\hline
\end{tabular}

SD (standard deviation), $\mathrm{N}=$ number.

Table (2) Ultrasonograhic findings of studied patients.

\begin{tabular}{|c|c|c|c|c|c|}
\hline \multirow[t]{2}{*}{ Ultrasonograhic findings } & \multicolumn{2}{|c|}{$\begin{array}{c}\text { Group I (treated) } \\
\qquad \mathbf{N}=\mathbf{2 0 0}\end{array}$} & \multicolumn{2}{|c|}{$\begin{array}{c}\text { Group II } \\
\text { (non treated) } \\
\mathbf{N}=\mathbf{2 0 0}\end{array}$} & \multirow[t]{2}{*}{ P-value } \\
\hline & $\mathbf{n}$ & $\%$ & $\mathbf{n}$ & $\%$ & \\
\hline Ascites & 1 & 0.5 & 2 & 1.0 & 1.0 \\
\hline Splenomegaly ( $\geq 13 \mathrm{~cm}$ ) & 32 & 16.0 & 43 & 21.6 & 0.15 \\
\hline$P V \geq 13 \mathrm{~mm}$ & 27 & 13.5 & 31 & 15.5 & 0.31 \\
\hline Hepatomegaly $(\geq 15 \mathrm{~cm})$ & 99 & 49.5 & 97 & 48.5 & 0.47 \\
\hline
\end{tabular}

PV (Portal vein), $\mathrm{N}=$ number.

Table (3) Child classification of studied patients.

\begin{tabular}{|c|c|c|c|c|c|}
\hline & \multicolumn{2}{|c|}{$\begin{array}{c}\text { Group I (treated) } \\
\quad \mathbf{N}=\mathbf{2 0 0}\end{array}$} & \multicolumn{2}{|c|}{$\begin{array}{c}\text { Group II (non treated) } \\
\text { N }=200\end{array}$} & \multirow[t]{2}{*}{ p-value } \\
\hline & $\mathbf{n}$ & $\%$ & n & $\%$ & \\
\hline Child A & 166 & 83.0 & 169 & 84.5 & 0.12 \\
\hline Child B & 34 & 17.0 & 31 & 15.5 & 0.21 \\
\hline
\end{tabular}

Table (4) Alpha-fetoprotein.

\begin{tabular}{|c|c|c|c|}
\hline & $\begin{array}{c}\text { Group I (treated) } \\
\mathbf{N}=\mathbf{2 0 0} \\
\text { Mean } \pm \text { SD } \\
\end{array}$ & $\begin{array}{c}\text { Group II (non treated) } \\
\mathrm{N}=\mathbf{2 0 0} \\
\text { Mean } \pm \text { SD } \\
\end{array}$ & p-value \\
\hline$\overline{\text { AFP }}$ & $35.81 \pm 117.98$ & $54.71 \pm 174.55$ & 0.011 \\
\hline
\end{tabular}

AFP (Alpha-fetoprotein), SD (standard deviation), $\mathrm{N}=$ number.

Table (5) The Development of Hepato-cellular carcinoma in the studied patients after 1 year of follow-up.

\begin{tabular}{cccccc} 
& \multicolumn{2}{c}{ Group I (treated) } & \multicolumn{2}{c}{ Group II (non treated) } & P-value \\
& & $\mathbf{N}=\mathbf{2 0 0}$ & $\mathbf{N}=\mathbf{2 0 0}$ & $\mathbf{0}$ & \\
\hline HCC cases & 11 & $5.5 \%$ & 22 & $11.0 \%$ & $\mathbf{0 . 0 4 6}$ \\
\hline
\end{tabular}

HCC (hepato-cellular carcinoma), $\mathrm{N}=$ number.

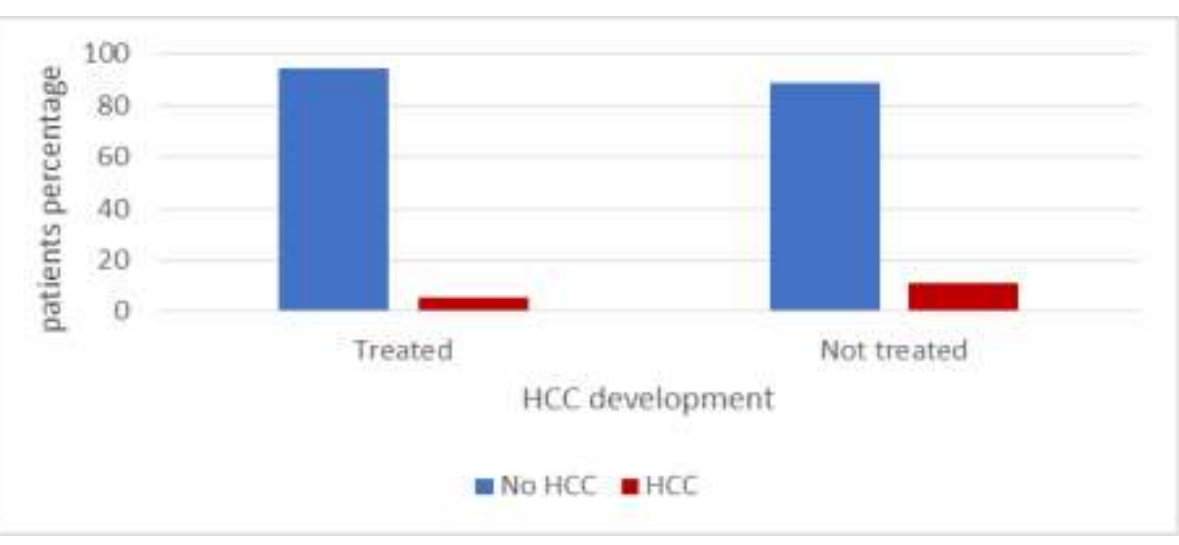

Fig. (1) Development of Hepato-cellular carcinoma in the studied patients. 
Table (6) Hepato-cellular carcinoma Criteria by triphasic computed tomography.

\begin{tabular}{|c|c|c|c|c|c|c|}
\hline & & \multicolumn{2}{|c|}{$\begin{array}{c}\text { Treated with cancer } \\
\text { (Group III) } \\
\text { N=11 }\end{array}$} & \multicolumn{2}{|c|}{$\begin{array}{c}\text { non treated with cancer } \\
\text { (Group IV) } \\
\mathbf{N}=22\end{array}$} & \multirow[t]{2}{*}{ P-value } \\
\hline & & $\mathbf{N}$ & $\%$ & $\mathbf{N}$ & $\%$ & \\
\hline \multirow{2}{*}{ Number } & single & 3 & $1.5 \%$ & 7 & $5.5 \%$ & 0.032 \\
\hline & multiple & 8 & $4.0 \%$ & 15 & $7.5 \%$ & 0.029 \\
\hline \multirow{3}{*}{ Size } & $<3 \mathrm{~cm}$ & 2 & $1.0 \%$ & 6 & $3.0 \%$ & 0.027 \\
\hline & $>\mathbf{3 c m}$ & 9 & $4.5 \%$ & 16 & $8.0 \%$ & 0.042 \\
\hline & Right lobe & 6 & $3.0 \%$ & 7 & $3.5 \%$ & 0.34 \\
\hline \multirow{2}{*}{ site } & Left lobe & 3 & $1.5 \%$ & 6 & $3.0 \%$ & 0.041 \\
\hline & Both lobes & 2 & $1.0 \%$ & 9 & $4.5 \%$ & 0.016 \\
\hline \multicolumn{2}{|c|}{ Associated LN } & 2 & $1.0 \%$ & 9 & $4.5 \%$ & 0.016 \\
\hline \multicolumn{2}{|c|}{ Associated PVT } & 3 & $1.5 \%$ & 8 & $4.0 \%$ & 0.019 \\
\hline
\end{tabular}

HCC (hepato-cellular carcinoma), $\mathrm{N}=$ number, LN (lymph node), PVT (portal vein thrombosis).

Table (7) Complete Blood Count (Group III and IV).

\begin{tabular}{|c|c|c|c|}
\hline & $\begin{array}{c}\text { Treated with cancer } \\
\text { (Group III) } \\
\mathbf{N}=\mathbf{1 1} \\
\text { Mean } \pm \text { SD }\end{array}$ & $\begin{array}{c}\text { non treated with cancer } \\
\text { (Group IV) } \\
\mathrm{N}=22 \\
\text { Mean } \pm \text { SD }\end{array}$ & P-value \\
\hline Hemoglobin & $13.86 \pm 1.41$ & $12.1 \pm 1.76$ & 0.03 \\
\hline WBCs & $6.49 \pm 1.62$ & $6.66 \pm 2.39$ & 0.13 \\
\hline Platelets & $206.45 \pm 76.94$ & $179.95 \pm 85.99$ & 0.37 \\
\hline
\end{tabular}

SD (standard deviation), $\mathrm{N}=$ number, WBCs: white blood cells.

Table (8) liver and kidney function tests (Group III and IV).

\begin{tabular}{|c|c|c|c|}
\hline & $\begin{array}{c}\text { treated with cancer } \\
\text { (Group III) } \\
\mathrm{N}=11 \\
\text { Mean } \pm \text { SD }\end{array}$ & $\begin{array}{c}\text { non treated with cancer } \\
\text { (Group IV) } \\
\mathrm{N}=22 \\
\text { Mean } \pm \text { SD }\end{array}$ & P-value \\
\hline ALT & $53.91 \pm 41.6$ & $61.91 \pm 48.95$ & 0.11 \\
\hline AST & $47.09 \pm 28.89$ & $46.95 \pm 19.6$ & 0.16 \\
\hline T.BIL & $0.79 \pm 0.51$ & $1.3 \pm 0.73$ & 0.001 \\
\hline D.Bil & $0.4 \pm 0.2$ & $0.3 \pm 0.09$ & 0.32 \\
\hline INR & $1.15 \pm 0.16$ & $1.11 \pm 0.14$ & 0.49 \\
\hline Albumin & $4.24 \pm 0.5$ & $4.14 \pm 0.38$ & 0.46 \\
\hline Creatinine & $0.84 \pm 0.21$ & $1.07 \pm 0.38$ & 0.002 \\
\hline
\end{tabular}

ALT (alanine transaminase), AST (aspartate transaminase), T.BIL. (total bilirubin), D.BIL (direct bilirubin) ,. INR(international normalized ratio) SD (standard deviation), $\mathrm{N}=$ number.

Table (9) Risk ratio for HCC Occurrence by Univariate Cox regression.

\begin{tabular}{cccccccc}
\hline Developed HCC & \multicolumn{2}{c}{ Not developed HCC } & Hazardous risk & \multicolumn{2}{c}{$\begin{array}{c}\text { 95\% for Hazardous } \\
\text { risk }\end{array}$} & P-value \\
$\mathbf{N}$ & $\%$ & $\mathbf{N}$ & $\%$ & & Lower & Upper & \\
\hline 22 & $11.0 \%$ & 178 & $89.0 \%$ & 3.465 & 0.002 & 7.733 & $\mathbf{0 . 0 0 2}$ \\
\hline
\end{tabular}

HCC (hepato-cellular carcinoma), $\mathrm{N}=$ number, $\mathrm{CI}$ (confidence interval).

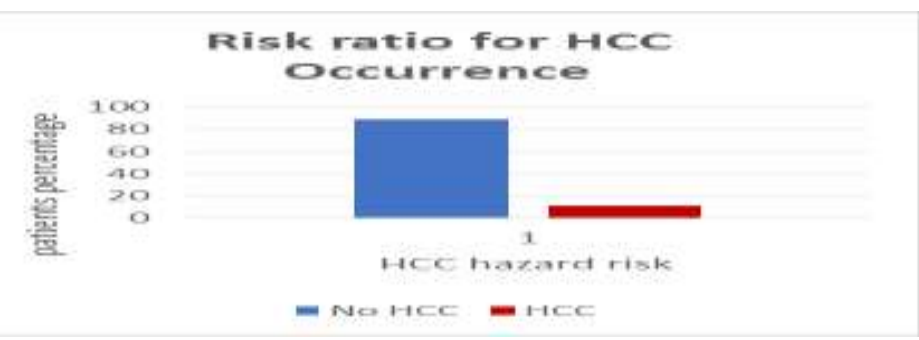

Fig. (2) HCC Occurrence risk ratio. 


\section{Discussion}

The purpose of this study was to clarify the possible effect of DAAs treatment on development of HCC in HCV cirrhotic patients.

After one year of follow up HCC developed more in not treated group with a significant difference between treated and not treated groups , as $11 \%$ of not treated group developed HCC compared to $5.5 \%$ only of treated group, similar results were detected by Ioannou et al., [8] who documented that HCC incidence was lower in the treated group who achieved SVR (0.43 per 100 patient-years) than in control group (1.15 per 100 patient-years), also, Kanwal et al., [9] documented that HCC developed in 183 patients with treatment during follow up at an annual incidence of 0.90 (or $0.90 \%, 95 \% \mathrm{CI}, 0.77-1.03 \%$ ), this rate was considerably lower than the 3.45 incidence rate in patients without treatment $(3.45 \%, 95 \%$ CI, $2.73-$ 4.18 ), in addition to Nahon et al., [10] who documented that there is a significant difference between treatment and control groups as regards HCC occurrence as number of patients with HCC at treatment group was 15 patients $(4.5 \%)$ while number of patients with $\mathrm{HCC}$ at not treated group was 154 patients $(35.1 \%)(\mathrm{P}<.001)$, also, Buonomo et al., [11] documented that direct acting antivirals treatment for hepatitis $\mathrm{C}$ virus infection does not increase the incidence of de novo hepatocellular carcinoma occurrence.

In this study, non treated group alphafetoprotein (AFP) is higher than treated group with a statistical significant difference, similar results were detected by Nahon et al., [10] who documented that there is a significant difference between treatment and control groups as regards after treatment alphafetoprotein as mean AFP level in $\mathrm{HCC}$ cases at treatment group is 9.0 [4.4-35.1] ng/mL and in non treated group is $19.6[8.2-102.0] \mathrm{ng} / \mathrm{mL}$ with $(\mathrm{P}$ $<.001)$.

In this study, treated group with HCC (group III) hemoglobin is higher than non treated group with HCC (group IV) with statistical significant difference, this can be explained as patients treated with DAAs were followed up with complete blood count monthly to follow the possibility of drug induced hemolysis and they received medical treatment to guard against anemia, also non treated patients showed higher rates of decompensation and bleeding tendency, similar results were detected by Kanwal et al., [9] who documented that there is a significant difference between study groups as regards after treatment Hemoglobin.

In this study, no statistical significant difference detected between treated group with HCC (group III) and non treated group with HCC (group IV) as regards white blood cells count and Platelets, Kanwal et al., [9] detected similar results that there is no significant difference between treated group with HCC and nontreated group with HCC as regards white blood cells, also, Innes et al., [12] documented that there is no significant difference between study groups as regards platelets.

In this study, non treated group with $\mathrm{HCC}$ (group IV) total bilirubin is higher than treated group with HCC (group III) with statistical significant difference, this can be explained by improvement in progression of cirrhosis after DAAs treatment, also, Pereira et al., [13] documented that DAA-induced SVR remains durable and is associated with an excellent clinical prognosis in patients with compensated advanced liver disease and with improvement or disease stabilization in decompensated patients. SVR is associated with a low risk of HCC occurrence or disease progression, especially in the presence of other causes of liver injury, in addition to Buonomo et al., [11] DAAs have a great efficacy in the eradication of $\mathrm{HCV}$ infection, these treatments were also effective in reducing the incidence of several complications of cirrhosis, such as ascites, jaundice and encephalopathy.

Also, non treated group with HCC (group IV) creatinine is higher than treated group with HCC (group III) with statistical significant difference. Similar results were detected by Reddy et al., [14] who documented that there is statistical significant difference regarding creatinine as treated patients with HCC group creatinine was lower than untreated patients with HCC group ( $<001)$. Also Ana et al., [15] documented that DAA treatment in patients with $\mathrm{HCV}$ improves kidney survival and reduces creatinine.

Although there is no statistical significant difference between treated group with HCC (group III) and non treated group with HCC (group IV) as regards ALT, AST, direct bilirubin, albumin and INR, using univariate cox regression, it was shown that no treatment was an independent factor affecting the risk of getting hepatocellular carcmmmmmmmmmmm,22,],2,m1 m[]m1minoma

(HCC), as cases not receiving the study treatment are at higher risk for developing $\mathrm{HCC}(\mathrm{HR}=3.4$, $\mathrm{P}=0.002$ ), this goes in agreement with Singer et al., [14] who documented that after implementation of inverse probability of treatment weighting and further adjustment for age, gender, baseline medical conditions (including liver conditions such as cirrhosis, portal hypertension and thrombocytopenia) and baseline medication use, the results were indicative of a reduced risk of liver b95\% CI: 0.73- 0.96), also, Buonomo et al., [11] documented that direct acting antivirals treatment for hepatitis $\mathrm{C}$ virus infection does not increase the incidence of de novo hepatocellular carcinoma occurrence, in addition to Pereira et al., [13] who documented that DAA-induced SVR remains durable and is associated with an excellent clinical prognosis in patients with compensated advanced liver disease and with improvement or disease 
stabilization in decompensated patients. SVR is associated with a low risk of HCC occurrence or disease progression, especially in the presence of other causes of liver injury, also, Shiha et al., [16] documented that the incidence of HCC is reduced in chronic hepatitis $\mathrm{C}$ genotype 4 patients with liver cirrhosis (F4) and advanced hepatic fibrosis (F3) who achieved SVR following DAA treatment. Study of large prospective cohort of HCV patients treated by DAAs with long follow-up period which showed that the annual incidence of HCC is $2.9 / 100$ per year (PY) in cirrhotic patients who achieved SVR following direct-acting antiviral treatment for hepatitis C. Also showed that treatment with DAAs is associated with reduced risk of HCC (2.72/100 py in patients with cirrhosis) compared with HCC incidence of $3.70 / 100$ py in cirrhotic patients who did not receive DAAs.

\section{Conclusion}

DAA treatment is not associated with a higher risk of $\mathrm{HCC}$ in cirrhotic patients with chronic $\mathrm{HCV}$ infection in the short-term. The occurrence of HCC is significantly decreased in patients treated with DAAs.

\section{References}

[1] H. Dai, "Association between homocysteine and non-alcoholic fatty liver disease in Chinese adults: a cross-sectional study," Nutr. J., vol. 15, pp. 102, 2016.

[2] N. Mokhtar, I. Gouda, and I. Adel, "Cancer pathology registry 2003-2004 and time trend analysis," Dep. Pathol. NCI,vol. 1, pp. 55, 2007.

[3] F. El-Zanaty and A. Way, "Egypt demographic and health survey 2008. Egyptian: Ministry of Health," Cairo ElZanaty Assoc. Macro Int., vol. 4, pp. 76-82, 2009.

[4] W. Alazawi, M. Cunningham, J. Dearden, and G. R. Foster, "Systematic review: outcome of compensated cirrhosis due to chronic hepatitis C infection," Aliment. Pharmacol. Ther., vol. 32, pp. 344-355, 2010.

[5] G. N. Ioannou, "Effectiveness of sofosbuvir, ledipasvir/sofosbuvir,

or paritaprevir/ritonavir/ombitasvir and dasabuvir regimens for treatment of patients with hepatitis $\mathrm{C}$ in the Veterans Affairs National Health Care System," Gastroenterology, vol. 151, pp. 457-471, 2016.

[6] G. Nunnari, A. Montineri, V. Portelli, F. Savalli, F. Fatuzzo, and B. Cacopardo, "The use of peginterferon in monotherapy or in combination with ribavirin for the treatment of acute hepatitis C," Eur Rev Med Pharmacol Sci, vol. 16,pp.1013-1016, 2012.
[7] S. Berretta, R. Fisichella, D. Spartà, A. Lleshi, and G. Nasti, "Primary liver cancer: clinical aspects, prognostic factors and predictive response to therapy," WCRJ, vol. 2, pp. e561, 2015.

[8] F. Su, L. A. Beste, P. K. Green, K. Berry, and G. N. Ioannou, "Direct-acting antivirals are effective for chronic hepatitis C treatment in elderly patients: a real-world study of 17487 patients," Eur. J. Gastroenterol. Hepatol.,vol.29,pp.686, 2017.

[9] F. Kanwal, J. Kramer, S. M. Asch, M. Chayanupatkul, Y. Cao, and H. B. El-Serag, "Risk of hepatocellular cancer in $\mathrm{HCV}$ patients treated with direct-acting antiviral agents," Gastroenterology, vol. 153, pp. 996-1005, 2017.

[10] P. Nahon, "Incidence of hepatocellular carcinoma after direct antiviral therapy for $\mathrm{HCV}$ in patients with cirrhosis included in surveillance programs," Gastroenterology, vol. 155, pp. 1436-1450, 2018.

[11] A. R. Buonomo, "Direct acting antivirals treatment for hepatitis $\mathrm{C}$ virus infection does not increase the incidence of de novo hepatocellular carcinoma occurrence: Results from an Italian real-life cohort (LINA cohort)," Medicine (Baltimore), vol. 99, pp. 76-81, 2020.

[12] H. Innes, "The risk of hepatocellular carcinoma in cirrhotic patients with hepatitis $\mathrm{C}$ and sustained viral response: role of the treatment regimen," J. Hepatol., vol. 68, pp. 646-654, 2018.

[13] T. P. Guedes, "Long-Term Follow-Up of Advanced Liver Disease after Sustained Virological Response to Treatment of Hepatitis C with Direct-Acting Antivirals: Outcomes from a Real-World Portuguese Cohort," GE-Portuguese J. Gastroenterol., vol. 27, pp. 149-159, 2020.

[14] A. W. Singer, "Direct-acting antiviral treatment for hepatitis $C$ virus infection and risk of incident liver cancer: a retrospective cohort study," Aliment. Pharmacol. Ther., vol. 47, pp. 1278-1287, 2018.

[15] A. Pérez de José, "Direct-acting antiviral therapy improves kidney survival in hepatitis $\mathrm{C}$ virus-associated cryoglobulinaemia: the RENALCRYOGLOBULINEMIC study," Clin. Kidney J., vol. 14, pp. 586-592, 2021.

[16] G. Shiha, N. Mousa, R. Soliman, N. NNH Mikhail, M. Adel Elbasiony, and $\mathrm{M}$. Khattab, "Incidence of $\mathrm{HCC}$ in chronic hepatitis $\mathrm{C}$ patients with advanced hepatic fibrosis who achieved SVR following DAAs: A prospective study," J. Viral Hepat., vol. 27, pp. 671-679, 2020. 